NASA Technical Memorandum 105791

114130

p. 9

\title{
Comparison of High Temperature, High Frequency Core Loss and Dynamic B-H Loops of a 2V-49Fe-49Co and a Grain Oriented 3Si-Fe Alloy
}

W.R. Wieserman

University of Pittsburgh at Johnstown

Johnstown, Pennsylvania

G.E. Schwarze

National Aeronautics and Space Administration

Lewis Research Center

Cleveland, Ohio

and

J.M. Niedra

Sverdrup Technology, Inc.

Lewis Research Center Group

Brook Park, Ohio

Prepared for the

27th Intersociety Energy Conversion Engineering Conference

cosponsored by the SAE, ACS, AIAA, ASME, IEEE, AIChE, and ANS

San Diego, California, August 3-7, 1992 


\section{COMPARISON OF HIGH TEMPERATURE, HIGH FREQUENCY CORE LOSS AND DYNAMIC B-H LOOPS OF A 2V-49Fe-49Co AND A GRAIN ORIENTED 3Si-Fe ALLOY}

\author{
W. R. Wieserman \\ University of Pittsburgh \\ at Johnstown \\ Johnstown, PA
}

\author{
G. E. Schwarze \\ National Aeronautics and \\ Space Administration \\ Lewis Research Center \\ Cleveland, $\mathrm{OH}$
}

\author{
J. M. Niedra \\ Sverdrup Technology, Inc. \\ NASA Lewis Research Center Group \\ Cleveland, $\mathrm{OH}$
}

\begin{abstract}
The design of power magnetic components such as transformers, inductors, motors, and generators, requires specific knowledge about the magnetic and electrical characteristics of the magnetic materials used in these components. Limited experimental data exists that characterizes the performance of soft magnetic materials for the combined conditions of high temperature, and high frequency over a wide flux density range. An experimental investigation of a $2 \mathrm{~V}-49 \mathrm{Fe}-49 \mathrm{Co}$ (Supermendur) and a grain oriented $3 \mathrm{Si}-\mathrm{Fe}$ (Magnesil) alloy was conducted over the temperature range of 23 to $300 \mathrm{C}$ and frequency range of 0.1 to $10 \mathrm{kHz}$. The effects of temperature, frequency, and maximum flux density on the core loss and dynamic B-H loops for sinusoidal voltage excitation conditions are examined for each of these materials. A comparison of the core loss of these two materials is also made over the temperature and frequency range investigated.
\end{abstract}

\section{INTRODUCTION}

The requirements of high efficiency, low specific mass, high reliability, and long life will need to be met for the Power Conditioning, Control, and Transmission (PCC\&T) subsystem of future high-capacity space power systems. High frequency operation of the power magnetic components will reduce their mass and high temperature operation of all power components will reduce the size and mass of the PCC\&T cooling radiator.

The designer of power magnetic components such as transformers, inductors, motors, generators, etc., requires specific knowledge about the electrical and magnetic properties of the magnetic materials used in these components. The dc magnetic properties, such as the "static" B-H hysteresis loop, are very useful as a guide for comparing different types of magnetic materials, but it is the ac magnetic properties which determine the usefulness of a magnetic material for a particular application. One of the most important ac properties required by the designer is the core loss as a function of magnetic flux density $\left(B_{m}\right)$, frequency (f), temperature (T), and type of waveform and excitation. Dynamic or ac B-H loops, or their decomposition into flux density and current excitation versus time waveforms, are also of interest since they give such information as saturation magnetization, coercivity, and remanence. The size of the dynamic loop gives an excellent qualitative assessment of the core loss, and the shape of the loop gives insight into stabilty characteristics, such as the presence of any dc offsets.

The NASA-Lewis Research Center (LeRC) has initiated an experimental program to characterize soft magnetic materials for the combined effects of temperature and frequency [1]. The temperature range for this program is 23 to $300 \mathrm{C}$ and the frequency range, dependent on type of material, is 0.1 to $50 \mathrm{kHz}$ for both sinusoidal and nonsinusoidal voltage excitation. A summary of experimental work by previous investigators of soft magnetic materials for temperatures up to $1000 \mathrm{C}$ is given in reference 2 . These previous investigations were primarily conducted for $\mathrm{dc}$ and $60 \mathrm{~Hz}$ conditions, with $3.2 \mathrm{kHz}$ being the highest frequency reported.

Under the present LeRC program, the combined effects of temperature ( 23 to $300 \mathrm{C}$ ) and frequency ( 1 to $50 \mathrm{kHz}$ ) have been reported for an $80 \mathrm{Ni}-\mathrm{Fe}$ crystalline alloy and two iron-based amorphous materials [3,4], and a grain oriented and nonoriented-grain $50 \mathrm{Ni}-50 \mathrm{Fe}$ crystalline alloy [5]. This paper reports on the experimental investigation of the combined effects of temperature $(23-300 \mathrm{C})$ and frequency $(0.1$ to $10 \mathrm{kHz})$ for sinusoidal voltage excitation on the core loss and dynamic B-H loop characteristics of a grain oriented $3 \%$ silicon iron alloy ( $3 \mathrm{Si}-\mathrm{Fe}$ ), and a $2 \%$ vanadium, $49 \%$ iron, $49 \%$ cobalt alloy $(2 \mathrm{~V}-49 \mathrm{Fe}-49 \mathrm{Co})$. Previous high temperature experimental investigation of these two alloys were confined to $\mathrm{dc}$ and low frequency characterization. The 3Si-Fe alloy was investigated during the late fifties for temperatures up to $750 \mathrm{C}$ for dc and $60 \mathrm{~Hz}$ conditions[6], and up to $500 \mathrm{C}$ for $\mathrm{dc}$ and $400 \mathrm{~Hz}$ conditions [7]. The 2V$49 \mathrm{Fe}-49 \mathrm{Co}$ alloy was investigated for temperatures up to $850 \mathrm{C}$ for dc and $60 \mathrm{~Hz}$ conditions in the late fifties [6], and an exhaustive investigation of this alloy was conducted in the early seventies for temperatures up to $900 \mathrm{C}$ for $\mathrm{dc}$ conditions [8]. The data reported in reference 6 showed that 
the 2V-49Fe-49Co alloy lost its outstanding magnetic properties at $25 \mathrm{C}$ after exposure to $800 \mathrm{C}$. However, the data reported in reference 8 did not confirm these results; instead the results in reference 8 showed that this alloy surprisingly maintained very good magnetic properties at $25 \mathrm{C}$ after exposure to $900 \mathrm{C}$.

\section{CORE LOSS APPROACHES}

The magnetic properties of ferromagnetic materials which include saturation magnetization, Curie temperature, permeability, remanence, coercive force, core loss, and in general, the size and shape of the B-H hysteresis loop, are affected by composition, impurities, mechanical strains, heat treatments, magnetic anneals, crystal structure, and crystal orientation. The amount of irreversible energy expended during cyclic magnetization of a ferromagnetic material is called the core loss and it makes its presence known through the generation of heat in the material's crystal structure. The B-H loop area is a graphical representation of the heat generated within the material. The core loss is generally normalized with respect to unit mass or volume and is referred to as the specific core loss (SCL). The explanation for core loss takes two different approaches: the classical and the domain theory approach. A brief description of domain theory will first be given.

The magnetic domain concept represents a ferromagnetic material as made up of small regions of magnetization called domains. The intensity of magnetization, that is, the magnetic moment per unit volume, of each domain is equivalent to the saturation or intrinsic magnetization of the bulk material. The magnetic flux density, or induction, below saturation is determined by the orientation of the magnetic moment of the domains with respect to the applied magnetizing field.

According to domain theory, there are two mechanisms which cause a change in the alignment or orientation of the magnetic moment of the domain: wall motion and domain rotation. In wall motion two domains which have differently directed magnetic moments will undergo a change in volume such that the domain with its magnetic moment most nearly aligned with the applied field will grow in volume at the expense of the other domain. Thus, wall motion causes an increase in the size of those domains whose magnetic moments are most nearly aligned with the applied field. Domain rotation is the turning or rotating of the magnetic moment of the domains out of certain preferred directions of the crystal into the direction of the applied field. The energy required to cause the change determines which of these mechanisms occurs. Wall motion requires less energy than domain rotation so wall motion dominates over domain rotation for low applied fields. The change in flux density per unit of applied magnetizing field is also greater for wall motion than for domain rotation.

The classical or conventional approach to core loss, postulated prior to the introduction of domain theory, separates the core loss into hysteresis and eddy current loss components. Hysteresis loss is defined as the energy (heat) expended in a ferromagnetic material as a result of magnetic irreversibility (hysteresis) when the flux density is cyclic. The area of the dc or static B-H hysteresis loop is proportional to the hysteresis loss. The eddy current loss is the energy (heat) expended by the circulating currents induced through the time variation of the magnetic flux in the core laminations or the convolutions of spirally wound tape cores. The total loss dependence on temperature is the sum of the temperature dependencies of the loss components. Classical theory shows that the eddy current loss is inversely proportional to the resistivity of the magnetic material. The resistivity of crystalline ferromagnetic materials increases with temperature, so classical theory predicts a decrease in eddy current loss for increasing temperature, assuming the interlaminar resistance does not degrade with temperature. However, classical theory does not develop a similar relationship between hysteresis loss and a temperature dependent intrinsic property of the ferromagnetic material.

The modern approach used to explain the cause of core loss is based on the domain theory. This approach regards the classical approach of loss separation as artificial primarily because the so called dc hysteresis loop is not "static." To obtain the "static" B-H loop requires a time variation of the applied magnetizing field whether it is an incremental step-function field, or a very slowly, smoothlyvarying field. The domain theory approach states that the core loss is caused by micro eddy currents associated with wall motion and domain rotation. Domain walls move smoothly until they encounter an irregularity in the crystal structure. The wall tends to stick or be pinned at such a lattice defect and cannot break away until sufficient energy is supplied by the external magnetizing field. When the stuck domain walls snap away from their pinning sites, they do so at relatively high velocities. The eddy current loss is proportional to wall velocity, and so high wall velocities give rise to high eddy current losses. No matter how slowly the B-H loop is traversed, as long as the magnetizing field is increased monotonically, these micro eddy currents will exist. There will always be a hysteresis loop of at least some minimum area, because it is not possible to control these micro eddy currents with arbitrary slowness.

\section{MATERIAL DESCRIPTION}

Silicon-iron (Si-Fe) alloys, sometimes referred to as electrical or silicon steels, essentially form the backbone of the electrical industry for power applications such as transformers, motors, generators, etc. Due to their production costs and because of their excellent ac properties at $50-60 \mathrm{~Hz}$, the Si-Fe alloys give a definite advantage over any other soft magnetic material for low frequency power applications.

Prior to 1900 the material used for power applications was ordinary iron which contained substantial impurities that severely degraded performance over time due to ageing effects. The big improvement in magnetic alloys for power applications came around 1900 when Barrett, Brown, and Hadfield [9] investigated the magnetic properties of Si-Fe alloys. Their investigations found that the addition of $\mathrm{Si}$ to Fe resulted in the following improvements: reduction in core loss, increase in permeability, and almost complete elimination of ageing effects. Si-Fe alloys with less than 
6.5\% Si have body centered cubic crystal structure. An increase in Si content is a trade-off between electrical and mechanical properties: electrically, an increase in Si causes a decrease in core loss and a decrease in saturation induction; mechanically, an increase causes a decrease in ductility, making it difficult to fabricate thin sheets from high Si content alloys.

There are basically two main types of Si-Fe ferromagnetic alloys: grain oriented and nonoriented grain. Nonoriented or isotropic Si-Fe alloys have magnetic properties that are practically the same in any direction in the plane of magnetization. Grain oriented or anisotropic Si-Fe alloys have preferred alignment of the grains (crystals) of the polycrystalline bulk material. The nominal $\mathrm{Si}$ content of grain oriented $\mathrm{Si}-\mathrm{Fe}$ alloys is $3 \%$. Two types of preferred orientation in Si-Fe alloys are possible. Historically, the first orientation developed was the cube-on-edge texture investigated by Goss [10]. This texture is produced through a special cold rolling and subsequent annealing process and imparts directionality to the magnetic properties such that these properties are vastly superior in the direction of rolling, but inferior in all other directions compared to a similar isotropic $\mathrm{Si}-\mathrm{Fe}$ alloy. The second type of grain oriented $\mathrm{Si}-\mathrm{Fe}$ alloy developed is called the cube-on-face texture and the advantage of this texture is that it has an easy direction of magnetization both parallel and perpendicular to the rolling direction. The commercialization of the cube-on-face textured Si-Fe alloy has never been realized because of processing difficulties and higher costs.

Grain oriented $\mathrm{Si}-\mathrm{Fe}$ alloys have more domains lying in the direction of the applied field so that the B-H loop of an oriented material tends to be substantially more rectangular in shape than a similar nonoriented material. Grain oriented Si-Fe alloys offer the advantage of reducing core size with subsequent reductions in the amount of other materials required in the fabrication of a power magnetics device.

The addition of cobalt to iron has the beneficial effect of increasing both the saturation magnetization, and the Curie temperature. Elmen [11,12] conducted a systematic investigation of the iron-cobalt alloy system and found that the 50Fe-50Co alloy, which he named Permendur, had outstanding magnetic properties, namely high permeability at high flux densities with low hysteresis loss, compared to iron. However, electrically, this alloy had poor resistivity, and mechanically, it had poor ductility.

White and Wahl [13] found that the addition of up to $2 \%$ vanadium to Permendur had no significant effect on the magnetic properties, but did significantly improve the electrical and mechanical properties. Electrically, the $2 \% \mathrm{~V}$ addition caused the resistivity to increase threefold and mechanically, this addition caused the ductility, workability, and machinability, to show marked improvements. As a result, sheets as thin as a few thousandths of an inch could be produced.

Gould and Wenny [14] found that purified 2VPermendur gave exceptional magnetic and physical properties. They called this alloy Supermendur and reported that it gave the highest saturation magnetization of any known alloy along with low coercive force, low hysteresis loss, high maximum permeability, and a rectangular hysteresis loop. This high purity alloy was found to workharden slowly so that it could be cold rolled from 0.090 -inch to less than 0.001 inch thickness without intermediate anneals and still retain its ductility. In addition, it was found that unannealed Supermendur was grain oriented in the direction of rolling, but that Supermendur annealed in the presence of a magnetic field was nonoriented with relatively large grains. A magnetic anneal tends to reduce core loss, square-up the B-H loop, and reduce the coercive force. The high cost of Supermendur, compared to grain oriented $3 \mathrm{Si}$ $\mathrm{Fe}$, precludes its use except for applications where cost is of secondary importance and where weight and volume are the driving factors such as in aerospace applications.

This experimental investigation used the grain oriented $3 \mathrm{Si}-\mathrm{Fe}$ alloy known as Magnesil, and the $2 \mathrm{~V}-49 \mathrm{Fe}-49 \mathrm{Co}$ alloy known as Supermendur. Similar grain oriented $3 \mathrm{Si}-\mathrm{Fe}$ alloys have the trade names Silectron, Microsil, Hypersil, and Supersil. A material similar to Supermendur is called Hiperco 50. Table 1 gives a comparison of some of the pertinent magnetic, electrical, thermal, and physical properties of Magnesil and Supermendur.

\section{EXPERIMENT DESCRIPTION}

Both the Magnesil and Supermendur materials were procured from commercial sources in the form of tape wound toroids. Three Magnesil and two Supermendur cores were tested in two separate experiments. The Magnesil toroids were wound from 0.001 inch thick by 0.25 inch wide tape with nominal dimensions of $O D=1.25$ inches and ID $=1.0$ inches. The Supermendur cores were similar except they had an OD of 1.375 inches. By Faraday's law, the maximum flux density $\left(B_{m}\right)$ was calculated as the ratio of flux to core magnetic cross-sectional area $\left(A_{c}\right) . \quad A_{c}$ was calculated from $A_{c}=\left(M / D \bar{\ell}_{m}\right)$ where $M$, the mass of the core, is measured with an analytical balance, $\mathrm{D}$ is the magnetic material's physical density, and $\bar{\ell}_{\mathrm{m}}$ is the mean path of the core determined from OD and ID measurements. The instrumentation and procedures used to conduct the tests and record the data, along with the equations used to calculate $B_{m}, H$, and SCL from the induced voltage and excitation current waveforms, are identical to that described in reference 3 .

A high temperature oil bath with its integrated temperature controller regulates the test core's ambient temperature. The bath is filled with a special $300 \mathrm{C}$ silicone oil into which the cores are completely immersed. With hindsight it is now apparent that the internal temperature of each core should have been measured to enable the determination of the core temperature rise above the ambient oil temperature. The temperature rise information would be of particular usefulness for the high frequency, high flux density measurements where overheating of the test core is most likely to occur. Future experiments will use a thermocouple imbedded within each test core so that the internal core temperature can be monitored at all times. However, for the data reported herein, every effort was made to prevent local heating of the test core by capturing 
the required induced voltage and exciting current waveforms in the minimum length of time. From these waveforms specific core loss (SCL) and the B-H loop data were obtained at $0.1,0.4,1,2.5,5,7.5$, and $10 \mathrm{kHz}$. For each frequency, the data were taken at $23 \mathrm{C}$ and thereafter in increments of $50 \mathrm{C}$ from 50 to $300 \mathrm{C}$. The data were again taken at $23 \mathrm{C}$ after the material's exposure to $300 \mathrm{C}$.

\section{EXPERIMENTAL RESULTS}

The experimental results for a single Magnesil and Supermendur test core are shown in Figures 1 through 7. For Magnesil, the $1 \mathrm{~K} 02$ test core data were selected because this core gave the lowest SCL in most cases compared to the other two test cores for all test frequencies and temperature. Occasional aberrations were observed in the SCL data for all three Magnesil cores. That is, the SCL would randomly deviate from the SCL versus $B_{m}$ curve established by the majority of the data points at a given frequency. These aberrations in the SCL data were attributed to test procedure in that they most likely occurred whenever the material was not in a symmetrically cyclically magnetized condition, that is, the B-H loop was not symmetrical with respect to the origin of the axes. It is not uncommon for a square loop type material, such as Magnesil, to exhibit this type of behavior. It is readily demonstrated that a dc offset will cause this nonsymmetry in the B-H loop, but in the absence of a dc offset, it is not completely clear what causes this type of behavior. A plausible explanation is that the material under certain magnetizing conditions retains a fixed level of residual magnetism, and its presence has the same effect on loop behavior as the application of a dc offset.

The SCL data for both Supermendur cores tended to track each other quite closely at all test frequencies and temperatures except at $300 \mathrm{C}$. For this temperature the SCL at $2.5,1$, and $0.4 \mathrm{kHz}$ for test core $1 \mathrm{R} 02$ was as much as $35 \%$ less than the SCL data for core 1R01. Because the test data for core 1R01 appeared to be more consistent than that for core $1 \mathrm{R} 02$, the test data for core 1R01 were chosen to be used in Figures 5, 6, and 7. The reason for this inconsistency in SCL at $300 \mathrm{C}$ was not established, and most likely, a retest of both cores at $300 \mathrm{C}$ will be required to determine the cause.

Figure 1 is a plot of the saturation flux density as a function of temperature taken at $\mathrm{f}=0.1 \mathrm{kHz}$ for 0.001 inch thick tape wound toroid of Supermendur and Magnesil. The horizontal curves in the plot clearly show that the saturation flux density for both of these materials is almost totally insensitive to temperature changes over the range of 23 to $300 \mathrm{C}$.

The effect of $B_{m}$ and $f$ on SCL at 23 and $300 \mathrm{C}$ is shown in the plots given in Figures $2 \mathrm{a}(23 \mathrm{C})$ and $2 \mathrm{~b}(300 \mathrm{C})$ for Magnesil and Figures 5a (23 C) and 5b (300 C) for Supermendur. For both materials these plots show that for a given $f$, the SCL tends to increase nearly linearly with $B_{m}$ on a log-log scale; and for a given $B_{m}$, the SCL increases as $f$ increases.

The effect of temperature and frequency on SCL at $0.5 \mathrm{~T}$ and $1.2 \mathrm{~T}$ is shown by the plots given in Figures $3 \mathrm{a}$ $(0.5 \mathrm{~T})$ and $3 \mathrm{~b}(1.2 \mathrm{~T})$ for Magnesil, and Figures $6 \mathrm{a}(0.5 \mathrm{~T})$ and $6 \mathrm{~b}(1.2 \mathrm{~T})$ for Supermendur. For both materials these plots show that an increase in temperature tends to cause small decreases in SCL over the temperature range of 23 to $300 \mathrm{C}$ except for Supermendur between 250 and $300 \mathrm{C}$. Here, for 0.4 and $1 \mathrm{kHz}$, the SCL shows a significant drop with temperature.

A representation of the dynamic B-H loops at 23 and $300 \mathrm{C}$ for selected frequencies is shown in Figures $4 \mathrm{a}(23 \mathrm{C})$ and $4 \mathrm{~b}(300 \mathrm{C})$ for Magnesil and Figures $7 \mathrm{a}(23 \mathrm{C})$ and $7 \mathrm{~b}$ $(300 \mathrm{C})$ for Supermendur. To enable valid comparisons, each of the B-H loops is drawn for the same $B_{m}$ of $1.2 \mathrm{~T}$. Comparison of the Magnesil B-H loops shows that the $300 \mathrm{C}$ loops are smaller in size than the $23 \mathrm{C}$ loops for equivalent frequencies. Comparison of the Supermendur B-H loops shows that the $300 \mathrm{C}$ loops are much more stable than the $23 \mathrm{C}$ loops, and also, that the $300 \mathrm{C}$ loops for equivalent frequencies are smaller in size than the $23 \mathrm{C}$ loops except at $2.5 \mathrm{kHz}$ where the $300 \mathrm{C}$ loop is somewhat larger than the $23 \mathrm{C}$ loop.

\section{COMPARISONS AND CONCLUSIONS}

A comparison of different soft magnetic materials in terms of SCL is valid only if each material has the same physical density; otherwise, core loss must be the basis for comparison. Because Magnesil has a lower density than Supermendur, the comparison of these two materials must be done on a core loss basis. Table 2 compares the core loss of the two materials, assuming that each core has the same $A_{c}$ and $\bar{\ell}_{m}$, and hence, the same volume. This implies that the ratio of the core masses equals the ratio of the materials' densities. If the Supermendur core is set equal to $1 \mathrm{lb}$., then the Magnesil core weighs $0.939 \mathrm{lbs}$.

Based on the trends observed in Table 2, the following comparisons and conclusions are made for the Magnesil and Supermendur materials fabricated from 0.001 inch thick tapes:

1. For a given $B_{m}$ and $f$, the core loss for Magnesil decreases with increasing temperature and the $300 \mathrm{C}$ core loss shows a decrease of $30-40 \%$ compared to the initial $23 \mathrm{C}$ values.

2. For a given $B_{m}$ and $f$, the Supermendur core loss decreases with increasing temperature for frequencies of $1 \mathrm{kHz}$ and less, but at $5 \mathrm{kHz}$ and above the trend is not consistent, for both increases and decreases in core loss occur for increasing temperature. For frequencies of $1 \mathrm{kHz}$ and less, the $300 \mathrm{C}$ core loss is $20-40 \%$ lower than the initial $23 \mathrm{C}$ loss.

3. The Magnesil core loss at $23 \mathrm{C}$ after the $300 \mathrm{C}$ exposure is only slightly higher than the initial $23 \mathrm{C}$ values. Thus, temperatures up to $300 \mathrm{C}$ did not severely degrade the loss characteristics. However, long term exposure at temperatures up to $300 \mathrm{C}$ would need to be investigated to determine if ageing causes any detrimental effects on the loss characteristics.

4. Unlike Magnesil, the Supermendur core loss at $23 \mathrm{C}$ after the $300 \mathrm{C}$ exposure tends to be lower than the initial $23 \mathrm{C}$ loss, and the amount of reduction depends on $\mathrm{B}_{\mathrm{m}}$ and $\mathrm{f}$, with decreases ranging from 15 to $50 \%$. These results would indicate that the exposure up to $300 \mathrm{C}$ actually 
improved the Supermendur core loss characteristics. However, long term ageing at $300 \mathrm{C}$ could possibly have detrimental effects and these loss reductions might not be realized. Also, it is possible that these loss reductions might not occur for Supermendur tape thicknesses greater than 0.001 inch. Hence, additional experiments would be required to determine the repeatability of the observed results.

5. A comparison of Magnesil and Supermendur at initial 23, 150, and $300 \mathrm{C}$ shows that Supermendur tends to have lower core loss at $0.1 \mathrm{kHz}$ and for high $\mathrm{B}_{\mathrm{m}}$ at 0.4 and $1 \mathrm{kHz}$; in all other cases, Magnesil tends to have lower losses. From core loss considerations for these temperatures, Magnesil would tend to be the preferred choice of materials, except Supermendur would clearly be the better choice for low $f$ and high $B_{m}$ operation.

6. A comparison of the Magnesil and Supermendur core loss at $23 \mathrm{C}$ after the $300 \mathrm{C}$ exposure gives an unexpected result: for equivalent $f$ and $B_{m}$ values, Supermendur always has lower core loss than Magnesil. Additional experimental investigations would be required to determine whether these low loss characteristics for Supermendur would be retained if it were again temperature cycled up to $300 \mathrm{C}$. Also, long term tests at elevated temperatures would need to be factored into the investigation to determine any ageing effects. Until such investigations are conducted, it would be premature to unequivocally state that Supermendur should be selected over Magnesil in terms of core loss considerations for the range of frequencies and flux densities investigated in this paper.

\section{REFERENCES}

1. Schwarze, G.E., "Overview of Space Power Electronics Technology Under CSTI High Capacity Power Program," Proc. Seventh Symposium on Space Nuclear Power Systems, Conf-900109, Albuquerque, NM, January 7-10, 1990.

2. Schwarze, G.E., Niedra, J.M., and Wieserman, W.R., "High Temperature, High Frequency Experimental Investigation of Soft Magnetic Materials," Proc. First Intemational High Temperature Electronics Conference, Albuquerque, NM, June 16-20, 1991.

3. Wieserman, W.R., Schwarze, G.E., and Niedra, J.M., "High Frequency, High Temperature Specific Core Loss and Dynamic B-H Hysteresis Loop Characteristics of Soft Magnetic Alloys," Proc. of the 25th Intersociety Energy Conversion Engineering Conference, Reno, NV, August 12-17, 1990.

4. Wieserman, W.R, Schwarze, G.E., and Niedra, J.M., "Comparison of High Frequency, High Temperature Core Loss and B-H Loop Characteristics of an $80 \mathrm{Ni}-\mathrm{Fe}$ Crystalline Alloy and Two Iron Based Amorphous Alloys," Proc. Eighth Symposium on Space Nuclear Power Systems, Conf-910116, Albuquerque, NM, January 6-10, 1991.
5. Wieserman, W.R., Schwarze, G.E., and Niedra, J.M., "Comparison of High Temperature, High Frequency Core Loss and Dynamic B-H Loops of Two 50 Ni-Fe Crystalline Alloys and an Iron-Based Amorphous Alloy," Proc. of the 26th Intersociety Energy Conversion Engineering Conference, Boston, MA, August 4-9, 1991.

6. Pasnak, M. and Lundsten, R.H., "Effects of Extremely High Temperatures on Magnetic Properties of Core Materials," U.S. Naval Ordnance Laboratory Report 6132, Silver Spring, MD, 10 July 1958.

7. Clark, J.J. and Fritz, J.F., "The Effect of Temperature on the Magnetic Properties of Silicon-Iron, Cobalt-Iron and Aluminum-Iron Alloys," Wright Air Development Center Technical Note 59-240, WPAFB, OH, July 1959.

8. Niedra, J.M. and G.E. Schwarze, "Magnetization, Anomalous Barkhausen Effect, and Core Loss of Supermendur Under High Temperature Cycling," IEEE Transactions on Magnetics, Vol. MAG-7, No. 4, December, 1971.

9. Barrett, W.F., Brown, W., Hadfield, R.A., "Electrical Conductivity and Magnetic Permeability of Various Alloys of Fe," Sci. Trans. Roy. Dublin Soc. 7, 67-126, 1900.

10. Goss, N.P., "New Development in Electrical Strip Steels Characterized by Fine Grain Structure Approaching the Properties of a Single Crystal," Transactions of the A.S.M., 23, 511-531, 1935.

11. Elmen, G.W., "Magnetic Material and Appliances," U.S. Patent 1,739,752, December 17, 1929.

12. Elmen, G.W., "Magnetic Alloys of Iron, Nickel, and Cobalt," Electrical Engineering, V.54, 1292-1299, 1935.

13. White, J.H., and Wahl, C.V., "Workable Magnetic Compositions Containing Principally Iron and Cobalt," U.S. Patent 1,862,599, June 14, 1932.

14. Gould, H.L.B. and Wenny, D.H., "Supermendur, A New Rectangular Loop Magnetic Material with High Flux Density and Low Coercive Force," Conference on Magnetism and Magnetic Material, 2nd, Boston, MA, October 17, 1956.

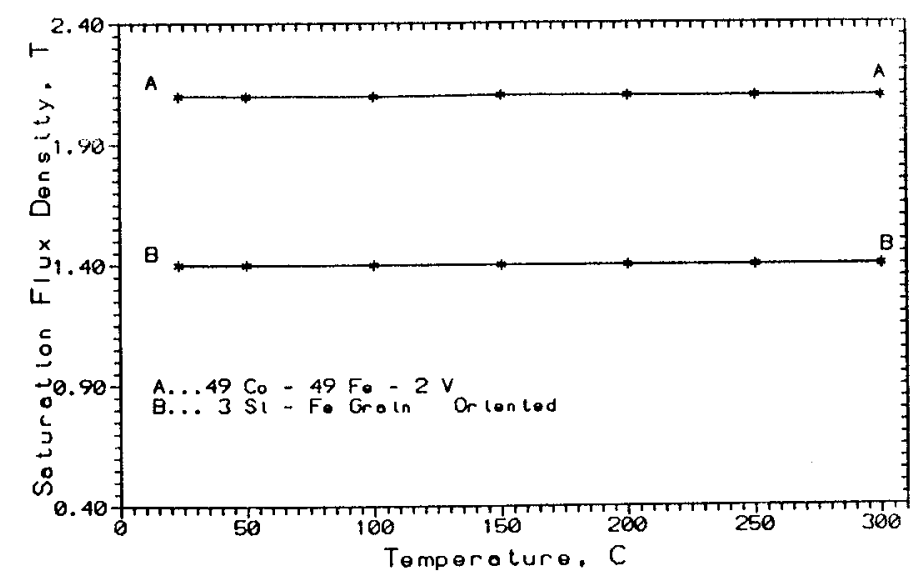

Figure 1. Saturation flux density $\left(B_{s}\right)$ versus temperature. $B_{s}$ taken from B-H saturation loops at $1 \mathrm{kHz}$. 


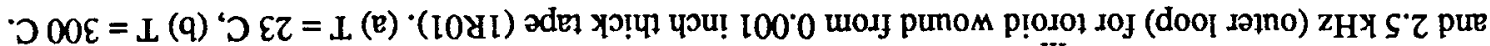

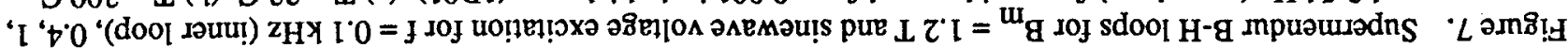

(q)

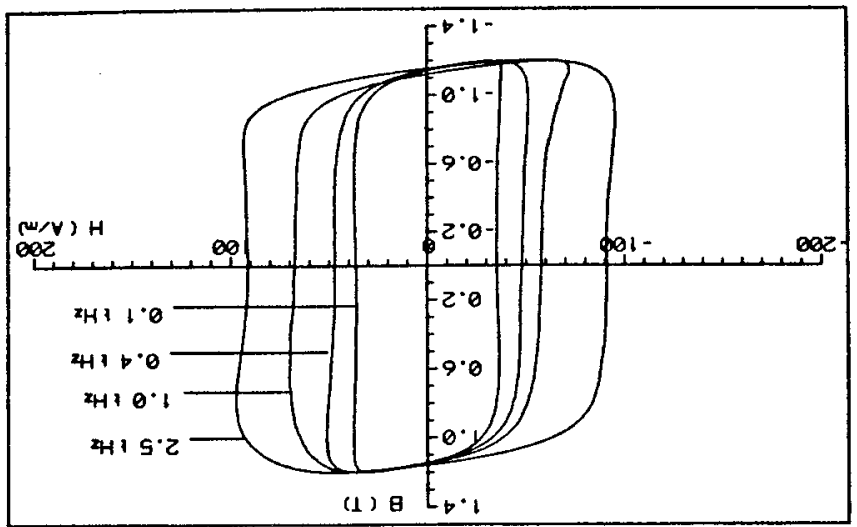

(e)

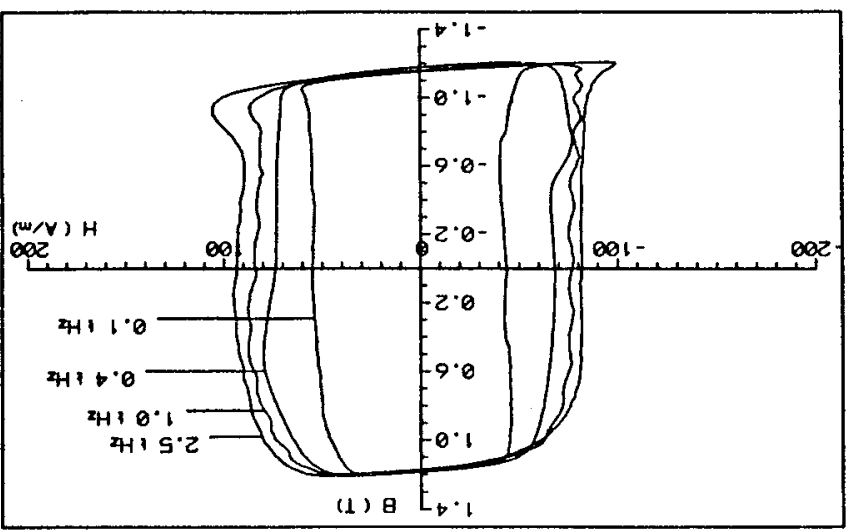

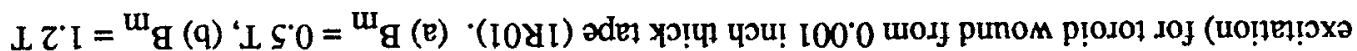

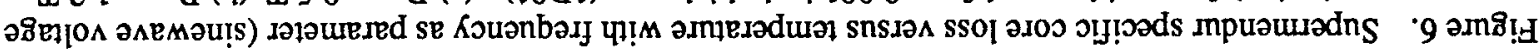

(q)

(כ) $\theta \operatorname{ung} 0 \operatorname{sed} \theta$

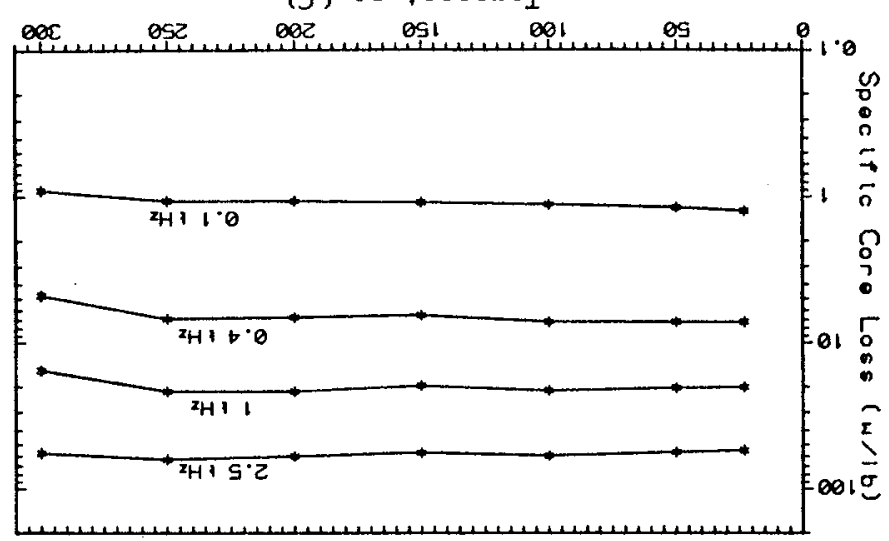

(e)

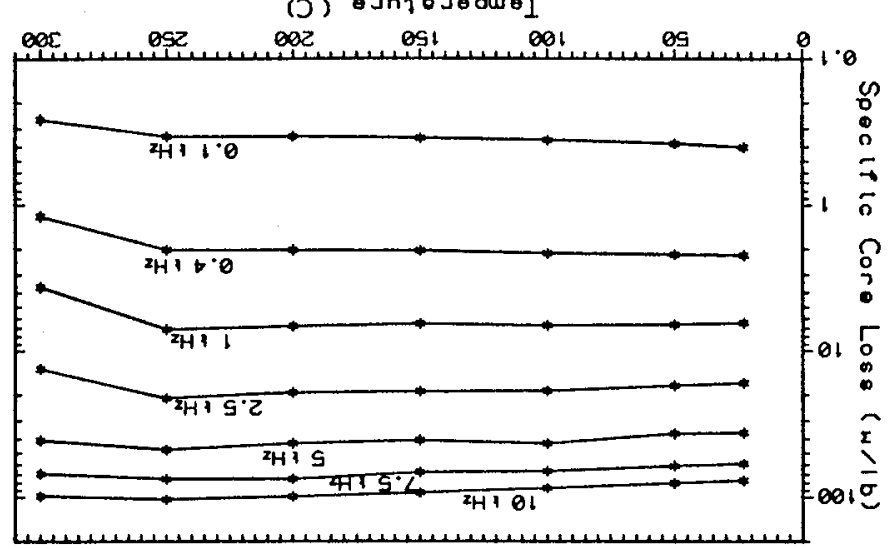

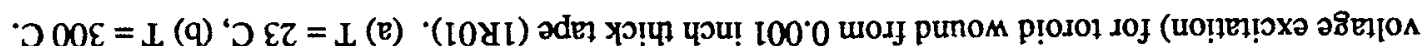

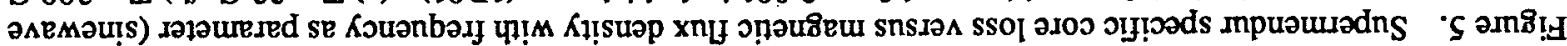

(q)

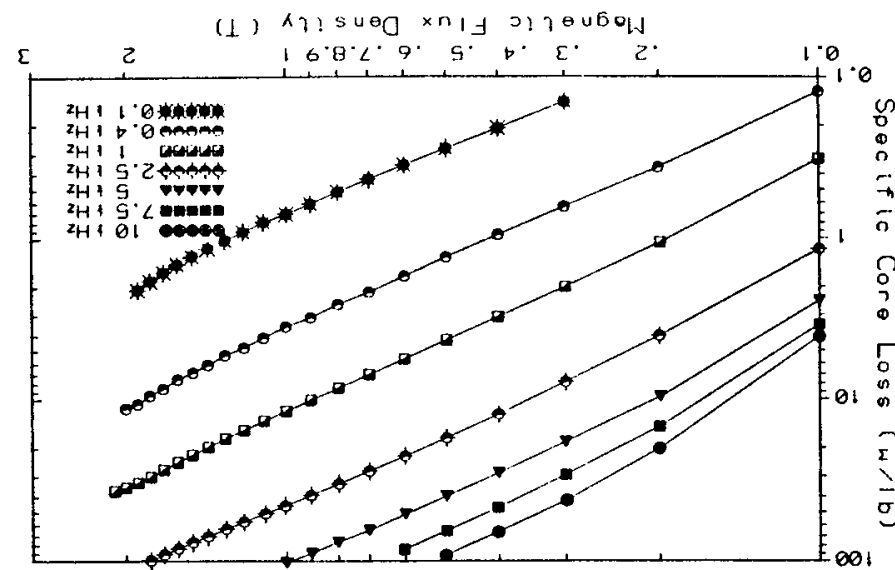

(e)

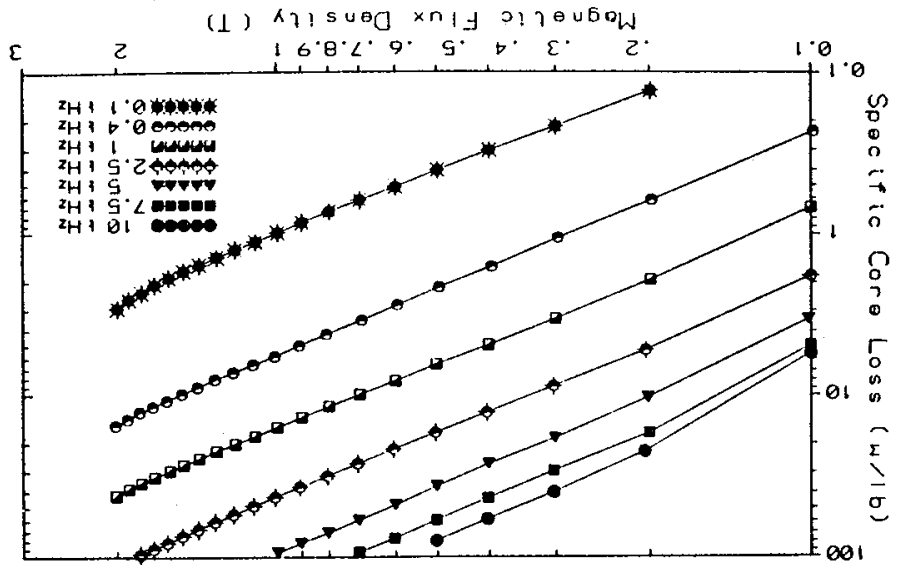




\begin{tabular}{|c|c|c|}
\hline Property & Magnesil| $\left.\right|^{(1)}$ & Supermendur ${ }^{(2)}$ \\
\hline $\begin{array}{l}\text { Composition } \\
\text { Structure } \\
\text { Saturation Induction } \\
\left.\text { (For } \mathrm{H}_{\mathrm{m}} \approx 240 \mathrm{Am}\right) \\
\text { Squareness Ratio }\left(\mathrm{B}_{\mathrm{r}} / \mathrm{B}_{\mathrm{m}}\right) \\
\text { Resistivity } \\
\text { Curie Temperature } \\
\text { Melting Point } \\
\text { Density } \\
0.2 \% \text { Yield Strength }\end{array}$ & $\begin{array}{c}3 \% \mathrm{Si}, 97 \% \mathrm{Fe} \\
\text { Crystalline } \\
1.5-1.8 \mathrm{~T}^{(2)} \\
\\
\geq 0.85 \\
50 \times 10^{-6} \Omega-\mathrm{cm} \\
750 \mathrm{C} \\
1475 \mathrm{C} \\
7.65 \mathrm{~g} / \mathrm{cm}^{3} \\
47.9 \times 10^{3} \mathrm{psi}^{(3)}\end{array}$ & $\begin{array}{c}49 \% \mathrm{Co}, 49 \% \mathrm{Fe}, 2 \% \mathrm{~V} \\
\text { Crystalline } \\
2.08-2.25 \mathrm{~T} \\
\geq 0.90^{(1)} \\
26 \times 10^{-6} \Omega-\mathrm{cm} \\
940 \mathrm{C} \\
1480 \mathrm{C} \\
8.15 \mathrm{~g}^{3} \mathrm{~cm}^{3} \\
185 \times 10^{3} \mathrm{psi}^{(4)}\end{array}$ \\
\hline $\begin{array}{l}\text { (1) Magnetics TWC-300T, } \\
\text { (2) The Arnold Engineering } \\
\text { (3) Magnetics, Thin Electri } \\
\text { (4) Spang Specialty Metals }\end{array}$ & $\begin{array}{l}\text { ual Featuring Tap } \\
\text { TC-101E Tape W } \\
\text { S-100. } \\
\text { letin SMA-9. }\end{array}$ & \\
\hline
\end{tabular}

\begin{tabular}{|c|c|c|c|c|c|c|c|c|c|}
\hline \multicolumn{10}{|c|}{$\begin{array}{l}\text { Table 2. Comparison of core loss of Magnesil and Supermendur for cores having } \\
\text { the same } A_{c} \text { and } T_{m} \text { with the Supermendur core weight set equal to } 1 \mathrm{lb} \text {. }\end{array}$} \\
\hline \multicolumn{10}{|c|}{ Core Loss (W) } \\
\hline \multirow[b]{2}{*}{$f(k H z)$} & \multirow[b]{2}{*}{$B_{m}(T)$} & \multicolumn{4}{|c|}{ Magnesil } & \multicolumn{4}{|c|}{ Supermendur } \\
\hline & & $23 C^{(1)}$ & $150 \mathrm{C}$ & $300 \mathrm{C}$ & $23 C^{(2)}$ & $23 C^{(1)}$ & $150 \mathrm{C}$ & $300 \mathrm{C}$ & $23 C^{(2)}$ \\
\hline \multirow[t]{4}{*}{0.1} & 2.0 & - & - & - & - & 2.9 & 2.4 & - & 3.2 \\
\hline & 1.4 & 2.9 & 2.6 & - & 2.9 & 1.6 & 1.4 & 1.1 & 1.4 \\
\hline & 1.0 & 1.2 & 1.0 & 0.81 & 1.2 & 0.98 & 0.82 & 0.70 & 0.81 \\
\hline & 0.6 & 0.53 & 0.40 & 0.32 & 0.49 & 0.51 & 0.43 & 0.35 & 0.38 \\
\hline \multirow[t]{4}{*}{0.4} & 2.0 & - & - & - & - & 15.4 & 14.4 & 11.3 & 10.9 \\
\hline & 1.4 & 11.8 & 10.3 & 8.2 & 12.3 & 8.9 & 8.1 & 6.1 & 6.1 \\
\hline & 1.0 & 4.6 & 4.1 & 3.3 & 5.0 & 5.7 & 5.0 & 3.5 & 3.5 \\
\hline & 0.6 & 1.9 & 1.7 & 1.3 & 2.0 & 2.8 & 2.5 & 1.7 & 1.7 \\
\hline \multirow[t]{4}{*}{1.0} & 2.0 & - & - & - & - & 41.8 & 41.4 & 35.0 & 28.3 \\
\hline & 1.4 & 31.2 & 27.5 & 21.2 & 33.3 & 24.7 & 24.2 & 19.6 & 16.9 \\
\hline & 1.0 & 12.2 & 10.7 & 8.7 & 13.1 & 15.8 & 15.4 & 11.7 & 9.7 \\
\hline & 0.6 & 5.2 & 4.4 & 3.3 & 5.2 & 8.2 & 7.8 & 5.6 & 4.5 \\
\hline \multirow[t]{3}{*}{5.0} & 1.0 & 74.3 & 65.5 & 52.6 & 79.8 & 93.6 & 101. & 102. & 65.2 \\
\hline & 0.6 & 30.7 & 27.1 & 21.3 & 31.5 & 47.8 & 52.3 & 51.3 & 30.9 \\
\hline & 0.2 & 3.9 & 3.6 & 2.6 & 4.9 & 10.4 & 12.3 & 9.6 & 4.8 \\
\hline \multirow[t]{3}{*}{10.0} & 0.6 & 72.7 & 60.3 & 50.8 & 82.5 & - & - & - & $\cdot$ \\
\hline & 0.4 & 41.1 & 33.0 & 25.0 & 42.8 & 58.5 & 65.7 & 66.0 & 36.5 \\
\hline & 0.2 & 12.1 & 10.1 & 7.1 & 11.6 & 22.4 & 26.5 & 20.2 & 10.9 \\
\hline
\end{tabular}


Public reporting burden for this collection of information is estimated to average 1 hour per response, including the time for reviewing instructions, searching existing data sources, gathering and maintaining the data needed, and completing and reviewing the collection of information. Send comments regarding this burden estimate or any other aspect of this Davis Highway, Suite 1204, Artington, VA 22202-4302, and to the Office of Management and Budgel, Paperwork Reduction Project (0704-0188), Washington, DC 20503.

\begin{tabular}{|l|c|c|}
\hline 1. AGENCY USE ONLY (Leave blank) & $\begin{array}{c}\text { 2. REPORT DATE } \\
\text { August } 1992\end{array}$ & $\begin{array}{r}\text { 3. REPORT TYPE AND DATES COVERED } \\
\text { Technical Memorandum }\end{array}$ \\
\hline
\end{tabular}

\section{TITLE AND SUBTITLE}

Comparison of High Temperature, High Frequency Core Loss and Dynamic B-H Loops of a $2 \mathrm{~V}-49 \mathrm{Fe}-49 \mathrm{Co}$ and a Grain Oriented $3 \mathrm{Si}-\mathrm{Fe}$ Alloy

\section{AUTHOR(S)}

W.R. Wieserman, G.E. Schwarze, and J.M. Niedra

\section{FUNDING NUMBERS}

WU-590-13-31
8. PERFORMING ORGANIZATION REPORT NUMBER

E-7221

National Aeronautics and Space Administration

Lewis Research Center

Cleveland, Ohio 44135-3191

10. SPONSORING/MONITORING AGENCY REPORT NUMBER

National Aeronautics and Space Administration

Washington, D.C. 20546-0001

NASA TM-105791

\section{SUPPLEMENTARY NOTES}

Prepared for the 27th Intersociety Energy Conversion Engineering Conference, cosponsored by the SAE, ACS, AlAA, ASME, IEEE, AIChE, and ANS, San Diego, California, August 3-7, 1992. W.R. Wieserman, University of Pittsburgh at Johnstown, Johnstown, Pennsylvania 15902. G.E. Schwarze, NASA Lew is Research Center, Cleveland, Ohio 44135. J.M. Niedra, Sverdrup Technology, Inc., Lewis Research Center Group, 2001 Aerospace Parkway, Brook Park, Ohio 44142. Responsible person, G.E. Schwarze, (216) 433-6117.

12a. DISTRIBUTION/AVAILABILITY STATEMENT 12b. DISTRIBUTION CODE

Unclassified - Unlimited

Subject Category 33

13. ABSTRACT (Maximum 200 words)

The design of power magnetic components such as transformers, inductors, motors, and generators, requires specific knowledge about the magnetic and electrical characteristics of the magnetic materials used in these components. Limited experimental data exists that characterizes the performance of soft magnetic materials for the combined conditions of high temperature, and high frequency over a wide flux density range. An experimental investigation of a $2 \mathrm{~V}-49-\mathrm{Fe}-49 \mathrm{Co}$ (Supermendur) and a grain oriented $3 \mathrm{Si}-\mathrm{Fe}$ (Magnesil) alloy was conducted over the temperature range of 23 to $300 \mathrm{C}$ and frequency range of 0.1 to $10 \mathrm{kHz}$. The effects of temperature, frequency, and maximum flux density on the core loss and dynamic B-H loops for sinusoidal voltage excitation conditions are examined for each of these materials. A comparison of the core loss of these two materials is also made over the temperature and frequency range investigated.

\section{SUBJECT TERMS}

Specific core loss; B-H hysteresis loops; Magnetic material; High temperature; High frequency; Magnetic measurements; Transformers; Power conditioning

\begin{tabular}{|c|c|}
\hline $\begin{array}{c}\text { 17. SECURITY CLASSIFICATION } \\
\text { OF REPORT }\end{array}$ & $\begin{array}{c}\text { 18. SECURITY CLASSIFICATION } \\
\text { OF THIS PAGE } \\
\text { Unclassified }\end{array}$ \\
Unclassified \\
\hline
\end{tabular}
19. SECURITY CLASSIFICATION OF ABSTRACT Unclassified

\begin{tabular}{|c|}
$\begin{array}{c}\text { 15. NUMBER OF PAGES } \\
10\end{array}$ \\
$\begin{array}{c}\text { 16. PRICE CODE } \\
\text { AO2 }\end{array}$ \\
20. LIMITATION OF ABSTRACT \\
\hline
\end{tabular}

NSN 7540-01-280-5500 